\title{
Youth and adult public views of dairy calf housing options
}

\author{
Rielle K. Perttu, 이 Beth A. Ventura, (1) and Marcia I. Endres* (요 \\ Department of Animal Science, University of Minnesota, St. Paul 55108
}

\begin{abstract}
The objective of this study was to explore views on dairy calf housing options among American youth and adults. Youth views were of interest because they are future consumers, yet their influence on livestock production practices is often overlooked. Participants 5 to $17 \mathrm{yr}$ of age $(\mathrm{n}=463)$ and $18 \mathrm{yr}$ or older $(\mathrm{n}=1,310)$ completed an in-person survey at the Minnesota State Fair (St. Paul, MN) in summer 2018. The survey was administered via Qualtrics survey software (Qualtrics, Provo, UT) using iPads (Apple, Cupertino, CA) and, in addition to collecting demographics, presented $3 \mathrm{im}-$ ages of calf housing options (individual, pair, or group) and asked participants to select their preferred option and indicate their reasoning for selection (youth), or acceptance for each option and reasoning for selection (adult). The PROC SURVEYFREQ of SAS (9.4; SAS Institute Inc., Cary, NC) was used for descriptive analysis. Rao-Scott chi-square tests (PROC SURVEYFREQ, SAS 9.4) were used to investigate relationships between demographics and housing preference or acceptance. Content analysis identified recurring themes to describe qualitative reasoning underlying dairy calf housing preference or acceptance. The median age of youth participants was $11 \mathrm{yr}, 61 \%$ were female, $82 \%$ were urban residents, and $63 \%$ did not have prior experience handling agricultural animals, but $83 \%$ had visited a farm in the past. Median age range of adult participants was 45 to $54 \mathrm{yr}, 65 \%$ were female, $82 \%$ urban residents, $41 \%$ completed a bachelor's degree, and $81 \%$ did not have prior experience handling agricultural animals, but $63 \%$ had visited a farm in the past. Overall, group housing was overwhelmingly preferred by youth participants $(80.1 \%)$, followed by pair $(14.3 \%)$ and individual housing $(5.6 \%)$. Youth who chose group housing most commonly cited reasons related to increased socialization (71.4\%) and space allowance (58.5\%). Housing preference of youth was not associated with age, gen-
\end{abstract}

Received October 9, 2019.

Accepted April 21, 2020.

*Corresponding author: miendres@umn.edu der, or prior visits to a farm. However, rural youth more frequently preferred individual housing compared with urban youth $(13.6 \pm 4.5 \% \mathrm{SE}$ vs. $5.1 \pm 1.3 \%$, respectively). Similarly, adult participants were most accepting of group housing for dairy calves $(75.8 \%$ of participants), with reasons focused on calves' ability to socialize and access to increased space allowance. Adult males, rural residents, and individuals with previous livestock handling experience more frequently accepted individual calf housing compared with females, urban residents, and individuals without previous livestock handling experience. These findings suggest that housing systems that enable greater degrees of behavioral freedom for calves may be more socially sustainable for the dairy sector.

Key words: calf housing preference, youth views, adult views

\section{INTRODUCTION}

Attempts have been made to understand the public's views about farm animal welfare in recent years (Cardoso et al., 2016; Wolf et al., 2016; Busch et al., 2017). As public interest in animal welfare increases, societal preferences are expected to exert increasing influence on livestock production practices (Vanhonacker et al., 2007). For example, voters in numerous states in the United States have voted to ban certain livestock housing systems (Smithson et al., 2014). It is crucial for the dairy sector to understand public views to help better align management practices with public expectations (Schweikhardt and Browne, 2001). Concerns about livestock agriculture arise in part as expressions of deeply held values relative to animal welfare. Values, which Schwartz (1992) described as "desirable, transsituational goals...that serve as guiding principles in people's lives," function as criteria used to judge methods of animal production (Boogaard et al., 2008). Hence, a clear description of concerns about livestock welfare can help identify values relative to animal care.

Public views toward dairy cattle welfare have been researched in Europe, Canada, and South America, with most work focused on issues specific to the dairy cow (Schuppli et al., 2014; Cardoso et al., 2017; Rob- 
bins et al., 2019). However, to our knowledge, little information is available on public views toward management of the dairy calf.

Dairy farms in the United States routinely house calves individually (NAHMS-USDA, 2016), but recently some producers have shifted to housing calves in pairs or groups, which has been shown to confer several welfare benefits without compromising calf health. For example, calves housed in groups have higher solid feed intake during the preweaning stage (Keil and Langhans, 2001; Costa et al., 2015) and greater weight gain after weaning (Warnick et al., 2010; Costa et al., 2014). Housing calves in pairs or groups also allows them greater opportunity to engage in social interactions and play (Babu et al., 2004; Costa et al., 2016). Pair and group housing may also reduce labor requirements for feeding calves and cleaning pens (de Passillé et al., 2004). In contrast, individual housing has been shown to lead to suboptimal social skills, creating difficulties for the calf in coping with novel situations later in life (De Paula Vieira et al., 2010; Costa et al., 2016).

Despite increasing evidence that pair and group housing offers welfare benefits to calves, little is known about how different stakeholders, including youth, perceive these housing options. Few peer-reviewed studies are available on youth concerns or values relative to dairy farming, much less to calf housing practices. Youth stakeholders are often overlooked in their power as industry influencers, even though they are future policy makers and consumers (Jamieson et al., 2015). Therefore, the objective of this study was to explore youth and adult public views of different calf housing options and reasons underlying preference or acceptance.

\section{MATERIALS AND METHODS}

A mixed-method survey was used to investigate dairy calf housing preferences (youth) or acceptance (adult) and values underlying calf housing preference or acceptance among fair goers attending the 2018 Minnesota State Fair in St. Paul, Minnesota. The study protocol (including the survey instrument) was approved by the University of Minnesota's Institutional Review Board under protocol 00003443. The Minnesota State Fair has an annual attendance of approximately 2 million people. Participants were recruited at the University of Minnesota Driven to Discover research building at the fair over five 7-h shifts between August 25 and September 2, 2018. As youth and adults neared our study area within the building, our research team approached them and briefly told them about the survey and asked if they were willing to participate. If youth answered yes, their accompanying parent or guardian was asked for consent. Individuals were eligible to participate in the study if they were able to read and write in English and were at least $5 \mathrm{yr}$ of age. The anonymous survey was administered via iPads (Apple, Cupertino, CA) and the data were collected and managed using Qualtrics survey software (Qualtrics, Provo, UT). Participants were sequentially assigned anonymous IDs upon starting the survey $(\mathrm{PY} 1=$ youth participant 1 and $\mathrm{PA} 1=$ adult participant 1). Participants received a small drawstring backpack or a cow-shaped stress-ball upon completion of the survey as an incentive to participate.

\section{Survey Description}

Survey questions were developed by the research team with the goal to develop a 10-min survey that would document preferences (youth) or acceptance (adults) and values relative to dairy calf housing. The draft survey instrument was piloted among animal science faculty and undergraduate students at the University of Minnesota, St. Paul, and questions were refined for additional clarity as needed. For the duration of the youth survey, parents/guardians could see their children but were asked to not help them with the survey instrument. Researchers were on hand if children needed clarification or help completing the survey (e.g., in using the iPad or navigating the Qualtrics platform). The youth survey consisted of 12 multiple-choice questions and 1 mandatory open-ended question to explain their housing preference. The adult survey was comprised of 17 multiple-choice questions and 3 optional open-ended questions to explain their acceptance of calf housing options.

Youth demographic data were collected on age, gender, area of residence, prior experience handling agricultural animals, prior experience visiting a farm, having a loved one who works in the dairy industry, pet ownership, and social media use (e.g., Facebook, Twitter, Instagram, Snapchat). Youth participants had the option to select "I don't want to say" for questions asking for their gender, prior experience handling agricultural animals, prior experience visiting a farm, having a loved one who works in the dairy industry, and pet ownership.

Adult demographic data were collected on age range, gender, highest level of education completed, household income range, area of residence, prior experience handling agricultural animals and visiting a farm, having a loved one who works in the dairy industry, pet ownership, and social media use. Adult participants had the option to opt out of answering questions about their age, gender, education, and income. 
If youth or adult participants indicated that they had worked with livestock previously or visited a farm with animals, probe questions asked them to specify animal type(s). Although participants were not asked about their knowledge related to dairy farming, they were asked to indicate if they had visited dairy-related locations at the fair (the Dairy Building, containing dairy-related exhibits and dairy food products; the Miracle of Birth Center, where fair attendees could observe birth of dairy calves and other animals; the Cattle Barn containing live cattle; and the Moo Booth, where they could see dairy cattle production displays and observe cows being milked). Finally, youth participants were asked if they enjoyed consuming dairy and plantbased alternative food products ("milks"), and adult participants were asked if they consumed conventional and organic dairy and plant-based "milks."

Both youth and adult participants were then shown 3 pictures (Figure 1) of calf housing options (individual, pair, and group). Youth were asked to choose their preferred housing option and indicate the reasoning behind their choice in a mandatory, open-ended text box. Youth participants could only select 1 of the 3 options due to time demands and to reduce cognitive burden on participants.

Adult participants evaluated the same pictures but were given the following statement: "For the following questions we will show you three types of calf housing. The type of housing influences two aspects: the farmer's ability to manage calves' health and nutrition and the calf's opportunity to socialize with other calves." This content was provided to control for varying knowledge among participants and in keeping with perceived welfare-relevant tradeoffs between the housing options.

Adults were shown the 3 pictures of dairy calf housing options (Figure 1) separately and in randomized order. Each picture was accompanied by brief descriptive statements as follows: for individual housing, "These dairy calves are housed individually, which enables farmers to manage each calf's health and nutrition; calves can see and hear other calves but have no physical contact"; for pair housing, "These dairy calves are housed in pairs, which could pose some challenges for managing health and nutrition; calves can freely socialize with each other"; and for group housing, "These dairy calves are housed in small groups, which could pose challenges for monitoring health; calves can freely socialize with individuals in the group." After each housing option, adults were asked to indicate their agreement (strongly disagree [1] to strongly agree [5]) to the statement "This housing option is acceptable to me" and invited to explain their selection in an optional text box.

Pictures were selected to be as consistent as possible in terms of environment surrounding the calf/calves (e.g., limited background visible; all indoors; similar lighting, housing material, and flooring; food and water sources available). However, we acknowledge that there were some minor differences, such as more barn visible in the group pen picture and cooler/dimmer tone in the individual pen picture. Pictures were obtained by University of Minnesota employees from a University of Minnesota facility (individual and pair housing) and a commercial dairy farm in Minnesota (group housing, consent provided by owner).

\section{Statistical Analysis}

Quantitative Analysis. The PROC SURVEYFREQ (SAS 9.4, SAS Institute Inc., Cary, NC) was used to estimate the totals and proportions of the categorical variables: gender, age category for youth (see below) or age range for adults, income range (adults), education (adults), area of residence, previous experience working
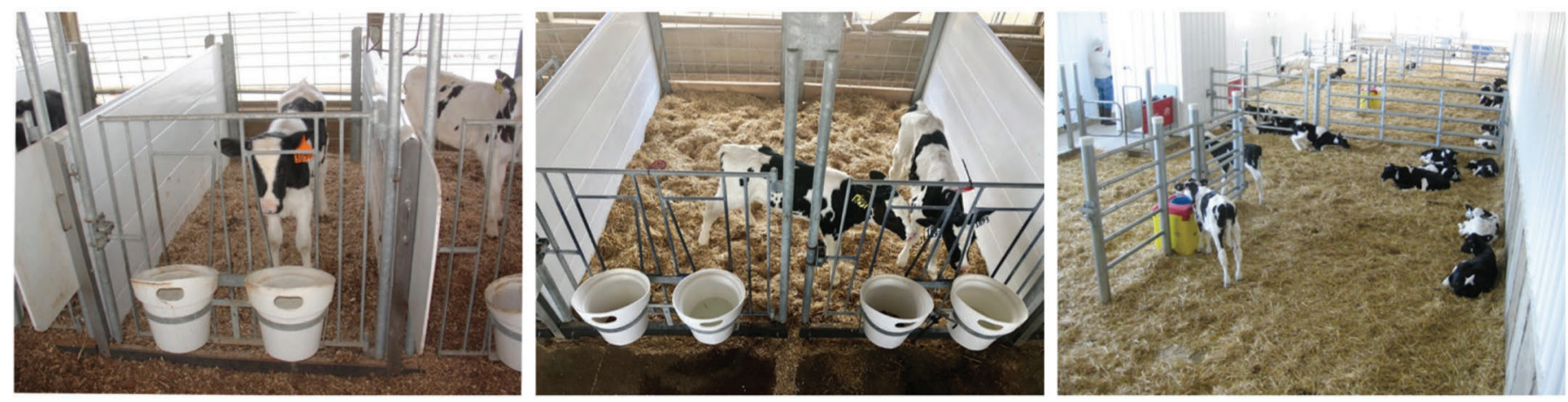

Figure 1. Dairy calf housing options shown to participants in the dairy calf housing survey at the 2018 Minnesota State Fair. Left: individual housing; center: pair housing; right: group housing. (Photo source: Marcia Endres, University of Minnesota). 
with agricultural animals, previous experience visiting a farm, if the participant had a loved one in the dairy industry, previous pet ownership, prior experience visiting cattle-related locations at the state fair, use of social media platforms, and consumption habits for dairy and plant-based alternative foods. Roedder (1981) has suggested that children make different purchase decisions in the self-centered stage (2-6 yr), preoperational stage (7-11 yr), and operational stage (12-17 yr). Therefore, for analysis of associations between age and housing preference in youth, we combined the self-centered stage and preoperational stage because we did not have a large enough sample of children in the self-centered stage (due to the requirement that participants be able to read), thereby creating 2 age categories of 5 to $11 \mathrm{yr}$ and 12 to $17 \mathrm{yr}$.

The Rao-Scott chi-square test (PROC SURVEYFREQ, SAS 9.4) was used to investigate relationships between demographic variables and housing preference or acceptance. Adult housing acceptance responses were collapsed into 3 categories (acceptance $=$ strong agreement and agreement, neutral $=$ neither agree nor disagree, nonacceptance $=$ disagreement and strong disagreement; Jeong and Lee, 2016) and treated as a categorical, discrete variable (Allen and Seaman, 2007) based on large sample size. Results are only reported for acceptance and nonacceptance as the 2 ends of the scale; neutral results are not reported. $P$-values $<0.05$ were considered statistically significant.

Qualitative Analysis. Content analysis was used for qualitative responses (open-ended questions) about values underlying housing preference or acceptance. The first stage of content analysis consisted of thoroughly reading, re-reading, and coding all text from the responses for emerging patterns (Coffey and Atkinson, 1994). Coding is the process of identifying and labeling phrases or statements within the free-text data contributed by participants. The first author coded all responses independently and then discussed the preliminary codes with the 2 co-authors. Once all authors agreed on preliminary codes throughout the data, a finalized codebook was created for the themes describing participant values and concerns relative to dairy calf housing options. After all coding was complete, the percentage of participants referencing each theme was calculated. Example responses that demonstrate themes are quoted below, followed by participant number in brackets. Particularly vague responses from which no further meaning could be gleaned (e.g., "it has what it needs" [PY50]), responses relative to the optics of how the systems looked (e.g., "cause looks cute" [PY434]), and infrequent, miscellaneous responses that were not well captured by the common themes were coded in initial stages but are not presented here.
The Rao-Scott Chi-Square test was used to investigate the relationship between demographic variables and the use of themes raised by youth participants to explain their housing preference. The relationship between adult demographics and use of themes was not evaluated because the open question on reason for acceptance was not mandatory.

\section{RESULTS}

\section{Description of Participants: Youth}

A total of 463 youth completed the survey and were included in the final analysis; a smaller number reported information on their gender $(\mathrm{n}=334)$ and area of residence $(\mathrm{n}=333)$. The median age of youth participants was $11 \mathrm{y}$ and the majority were female (60.8\%), had lived most of their lives in urban or suburban settings $(82.3 \%)$, had owned a pet in the past or currently owned a pet $(89.6 \%)$, and used at least 1 social media platform $(56.8 \%)$. Most had previously visited a farm with animals $(83.2 \%)$ and at least 1 dairy-related state fair location $(76.2 \%)$ but had not regularly worked with or handled farm animals (62.6\%), nor did they have loved ones who worked in the dairy industry $(75.6 \%)$. The majority (94.4\%) indicated that they enjoyed consuming dairy products, and $47.1 \%$ enjoyed consuming dairy alternatives such as almond, soy, or other plantbased beverages.

\section{Description of Participants: Adults}

A total of 1,310 adults completed the survey and were included in the final analysis. The majority of participants were female (64.9\%), 34.8\% were male, and $0.3 \%$ were gender nonconforming or had transitioned. The median age range was 45 to $54 \mathrm{yr}, 41.3 \%$ of participants had completed a bachelor's degree, $81.5 \%$ had lived most of their lives in an urban setting, and median household income was $\$ 80,000$ to $\$ 89,999$. Most $(80.7 \%)$ adults had not worked with or handled farm animals, but $62.9 \%$ had visited a farm with animals. The majority $(78.5 \%)$ did not have a loved one who worked in the dairy industry, and $94.0 \%$ had owned a pet in the past or currently owned a pet. Most (89.2\%) had visited at least 1 dairy-related state fair location, $83.5 \%$ used at least 1 social media platform, $93.7 \%$ indicated that they consumed dairy products such as milk, cheese, yogurt, butter, or ice cream, and $52.9 \%$ indicated that they did not drink any dairy-substitute products (almond beverage, soy beverage, or other plant-based beverages). Supplemental Table S1 (https: //doi.org/10.3168/jds.2019-17727) shows more detail for adult demographics. 


\section{Relationship Between Demographics and Calf Housing Preference: Youth}

Most youth selected group housing as their preferred choice $(80.1 \%)$, followed by pair $(14.3 \%)$ and individual housing (5.6\%). No relationship was found between calf housing preference and any demographics except area of residence. Area of residence was associated with a preference for individual calf housing $(P=0.026)$; rural youth more frequently preferred individual calf housing compared with urban/suburban youth $(13.6 \pm 4.5 \% \mathrm{SE}$ vs. $5.1 \pm 1.3 \%)$. Area of residence was also associated with a preference for pair calf housing $(P=0.021)$, with urban youth more frequently preferring pair housing compared with rural youth $(15.3 \pm 2.2 \%$ vs. $6.8 \pm$ $3.3 \%)$.

\section{Relationship Between Demographics and Calf Housing Acceptance: Adults}

Group housing also garnered the most acceptance among adults $(75.8 \%$ of participants accepted this option) followed by pair housing $(66.0 \%)$ and individual housing (31.5\%). No relationship was found between acceptance for any type of calf housing and age range, education, household income, or previous pet ownership. However, gender, area of residence, previous livestock handling experience, having a loved one in the dairy industry, prior experience visiting dairy-related state fair locations, and social media presence were all associated with acceptance for individual calf housing. More adult males accepted individual calf housing compared with females and gender-nonconforming participants (38.8 $\pm 2.3 \%$ vs. $27.6 \pm 1.5 \%$, respectively; $P<0.001$ ), as did rural compared with urban residents $(43.0 \pm 3.2 \%$ vs. $28.8 \pm 1.4 \%$, respectively; $P<0.001$ ). Acceptance of individual housing was also more frequent among adults with prior livestock handling experience (49.2 \pm $3.2 \%$ ) versus those without previous experience $(27.3 \pm$ $1.4 \% ; P<0.001)$; those with a loved one in the dairy industry $(44.4 \pm 3.0 \%)$ versus those without a loved one in the industry $(27.9 \pm 1.4 \% ; P<0.001)$; and those who had not visited dairy-related state fair locations $(40.1 \pm 4.1 \%)$ compared with those who had visited $(30.4 \pm 1.3 \% ; P=0.006)$. Finally, acceptance was more frequent among adults who did not use any of the listed social media platforms $(40.7 \pm 3.3 \%)$ compared with social media users $(29.6 \pm 1.4 \% ; P=0.003)$.

Adult acceptance for pair housing was associated with gender, previous livestock handling experience, and previous experience visiting a livestock farm. As with individual housing acceptance, more males accepted pair calf housing compared with females and gender nonconforming participants $(68.9 \pm 2.2 \%$ vs. $64.5 \pm 1.6 \%$, respectively; $P=0.046)$. Acceptance was also more frequent among those with prior livestock handling experience $(72.0 \pm 2.8 \%)$ and who had previously visited a farm $(68.8 \pm 1.6 \%)$, compared with those without livestock handling experience $(64.4 \pm 1.5 \%$; $P$ $=0.040)$ and who had never visited a farm, respectively $(61.0 \pm 2.2 \% ; P=0.016)$. No associations were found between demographics and adult acceptance of group housing.

\section{Reasons for Calf Housing Preferences: Youth}

Youth often included more than 1 theme in their reasons to support their housing preference (Table 1), and often used similar themes regardless of housing preference; for example, space allowance and affective state were mentioned in support of both pair and group housing.

Individual Housing. Individual housing was preferred by a minority of youth (5.6\% of participants).

Table 1. Youth participants' use of themes to justify preference of housing options for dairy calves ${ }^{1}$

\begin{tabular}{|c|c|c|c|c|}
\hline Theme & Description of theme & $\begin{array}{l}\text { Individual } \\
\text { housing }\end{array}$ & $\begin{array}{c}\text { Pair } \\
\text { housing }\end{array}$ & $\begin{array}{l}\text { Group } \\
\text { housing }\end{array}$ \\
\hline Affective state & $\begin{array}{l}\text { Housing option promoted positive feelings such as happiness and } \\
\text { avoidance of negative feelings such as stress and loneliness }\end{array}$ & $\mathrm{N} / \mathrm{A}$ & 19.7 & 5.4 \\
\hline Being alone & $\begin{array}{l}\text { Being housed alone was preferred for calves because they have } \\
\text { their own private space, away from other calves }\end{array}$ & 19.2 & $\mathrm{~N} / \mathrm{A}$ & $\mathrm{N} / \mathrm{A}$ \\
\hline Calf health & $\begin{array}{l}\text { Calves having individualized attention for treatment and } \\
\text { nutrition, controlling for disease, and overall better health } \\
\text { monitoring }\end{array}$ & 19.2 & $\mathrm{~N} / \mathrm{A}$ & $\mathrm{N} / \mathrm{A}$ \\
\hline Environmental quality & $\begin{array}{l}\text { Allusion to housing characteristics with limited other detail, food } \\
\text { or water availability, or safety of housing }\end{array}$ & 38.5 & 24.2 & 11.6 \\
\hline Space allowance & Space allowance as adequate & $\mathrm{N} / \mathrm{A}$ & 16.7 & 58.5 \\
\hline Socialization & $\begin{array}{l}\text { Description of play behavior or interaction between the calves and } \\
\text { having a friend or family member }\end{array}$ & $\mathrm{N} / \mathrm{A}$ & 31.8 & 71.4 \\
\hline
\end{tabular}

${ }^{1}$ Percentage of respondents. $\mathrm{N} / \mathrm{A}=$ the theme was not mentioned in reasons for preference or acceptance of housing options. 
These individuals focused on 3 themes in support of individual housing (in decreasing order of frequency): environmental quality, calf health, and being alone.

Youth who preferred individual housing most commonly referenced perceived environmental quality (used in $38.5 \%$ of responses in support of individual housing). This theme referenced specific, often physical attributes or provisions of the housing design, such as structures, food or water, organization, or perceived safety of the housing (e.g., "it is $[a]$ suitable living area" [PY52] and "they have [their] crates" [PY267]).

Themes of both calf health and being alone were mentioned by $19.2 \%$ of youth who preferred individual calf housing. These participants valued individual housing because it was viewed as the most optimal way to manage calves' health and nutrition (e.g., "limiting contact prevents spreading [of] germs and you can keep a better profile on them if one won't drink, [if one is] sick, etc." [PY465]). Likewise, those who preferred individual housing valued that calves were allowed to be alone, in their own private space and away from other calves (e.g., "they are secluded" [PY446]).

Pair Housing. A small portion of youth (14.3\%) preferred pair housing of calves, using 5 themes to justify their selection (in decreasing order of frequency): socialization, compromise between housing systems, environmental quality, affective state, and space allowance.

Those preferring pair housing most commonly cited socialization (31.8\% of participants with this preference) and provided some description of the system as allowing play or interaction between calves, or calves needing a friend or companion. For example, participants said that they preferred pair housing "because he had a friend" [PY455]. Youth who preferred pair housing also appeared to favor the compromise offered between individual and group housing $(28.2 \%$ of participants; e.g., "is not super crowded but it isn't isolated either" [PY331]). Similar to those who preferred individual housing, attributes related to environmental quality were also cited by $24.2 \%$ of those who chose pair housing (e.g., "plenty of food and water [for the calves]" [PY337]).

Youth also stated that they preferred pair housing due to how it might affect the calf's affective state (19.7\% of participants), for example by preventing negative feelings such as stress or loneliness that could arise from a more barren social environment (e.g., "they shouldn't be alone because they get depressed" [PY436]). Space allowance was also mentioned $(16.7 \%)$ in support of pair housing (e.g., "[calves] have a good [amount of] space for the both of them" [PY149]).

Group Housing. Most youth (80.1\%) chose group housing as their preferred calf housing option and raised 4 themes to support their choice (in decreasing order of frequency): socialization, space allowance, environmental quality, and affective state.

As with pair housing, those who chose group housing most commonly (71.4\%) mentioned the theme of socialization, referencing multiple calves in the pen or positive interaction between calves (e.g., "the calves can play and socialize which is important to all animals" [PY8]). Youth who chose group housing also commonly referenced space allowance $(58.5 \%)$ provided by this system (e.g., "it had a lot of space compared to the other ones" [PY427]) or referenced individual locomotive behaviors that are possible only through increased space ("more space to run around" [PY24]). In addition, $11.6 \%$ of those who preferred group housing referenced elements related to environmental quality. Less commonly, youth who preferred group housing referenced affective state (5.4\%; e.g., "because [there is more] than one calf $\left[\begin{array}{ll}\text { so } & i t\end{array}\right]$ is not lonely, when they are together it makes them feel at home" [PY71]).

\section{Reasons for Calf Housing Acceptance: Adults}

As with youth participants, adults often included more than 1 theme in their response and used similar themes to rationalize their acceptance of different calf housing options (Table 2).

Individual Housing. $31.5 \%$ of adults stated that they agreed or strongly agreed that individual housing was acceptable to them; $15.5 \%$ of these chose to provide the reasoning behind their choice. A total of 5 themes were identified in response to accepting individual calf housing (in decreasing order of frequency): conditional acceptance, calf health, environmental quality, visual/ auditory interaction, and space allowance.

Adults who accepted individual calf housing most commonly cited conditional acceptance of individual housing (32.8\%; e.g., "as long as it's just for a while" [PA964]). Others focused on calf health (29.7\%; i.e., that individual calf housing was "best for controlling diseases and nutrition intake" [PA1124]). Similar to youth participants, adults who accepted individual calf housing also did so due to perceived benefits related to environmental quality (21.9\%; e.g., this option was "safe and clean" [PA812] and "it protects the animal" [PA728]). Fewer (12.5\%) adults accepted individual housing because it at least provided visual/auditory interaction for calves (e.g., "they are still in [the] vicinity of other [calves]" [PA499]). Relatively few adults who accepted individual housing did so because of adequate space allowance $(4.7 \%)$.

Pair Housing. Most adults (66.0\%) accepted pair housing, with $16.3 \%$ choosing to provide reasons for their decision. Those who accepted pair housing focused 
Table 2. Adult participants' use of themes to justify acceptance of housing options for dairy calves ${ }^{1}$

\begin{tabular}{|c|c|c|c|c|}
\hline Theme & Description of theme & $\begin{array}{l}\text { Individual } \\
\text { housing }\end{array}$ & $\begin{array}{c}\text { Pair } \\
\text { housing }\end{array}$ & $\begin{array}{l}\text { Group } \\
\text { housing }\end{array}$ \\
\hline Calf health & $\begin{array}{l}\text { Calves having individualized attention for treatment and } \\
\text { nutrition, controlling for disease, and overall better health } \\
\text { monitoring }\end{array}$ & 29.7 & $\mathrm{~N} / \mathrm{A}$ & $\mathrm{N} / \mathrm{A}$ \\
\hline $\begin{array}{l}\text { Compromise between } \\
\text { housing systems }\end{array}$ & $\begin{array}{l}\text { A balance between socialization opportunities for calves and ease } \\
\text { of management for producer }\end{array}$ & $\mathrm{N} / \mathrm{A}$ & 15.6 & $\mathrm{~N} / \mathrm{A}$ \\
\hline Conditional acceptance & Housing system as acceptable for a temporary amount of time & 32.8 & 18.4 & 18.6 \\
\hline Space allowance & Space allowance as adequate & 4.7 & 9.9 & 32.8 \\
\hline Socialization & $\begin{array}{l}\text { Description of play behavior or interaction between the calves } \\
\text { and having a friend or family member }\end{array}$ & $\mathrm{N} / \mathrm{A}$ & 56.0 & 50.8 \\
\hline $\begin{array}{l}\text { Visual/auditory } \\
\text { interaction }\end{array}$ & $\begin{array}{l}\text { Housing option as acceptable because calf was near its peers and } \\
\text { could visually see or hear other calves; or mention of calves not } \\
\text { needing physical contact }\end{array}$ & 12.5 & $\mathrm{~N} / \mathrm{A}$ & $\mathrm{N} / \mathrm{A}$ \\
\hline
\end{tabular}

${ }^{1}$ Percentage of those participants who strongly agree or agree with the statement "This housing is acceptable to me." N/A = the theme was not mentioned in reasons for preference or acceptance of housing options.

on similar themes as those used for individual calf housing (in decreasing order of frequency): socialization, conditional acceptance, compromise between housing systems, environmental quality, and space allowance.

Those who accepted pair housing most commonly referenced socialization $(56.0 \%)$ in the form of play behavior, interaction between calves, or having a friend or family member (e.g., "it shows the freedom that calves have to socialize with other calves which is healthy for their mentality" [PA709]). Others conditionally accepted pair housing (18.4\%), as long as it was "not long term" [PA1209]. Some adults (15.6\%) also saw pair housing to offer a compromise between housing systems (e.g., "some space, some contact, but with the chance for the farmer to get some sense of feeding; not so much mixing with others that infectious diseases are easily spread" [PA1063]). As with individual housing, a few also accepted pair housing because of environmental quality $(9.9 \%)$, whereas others found pair housing to provide acceptable space allowance $(9.9 \%)$.

Group Housing. The majority of adults (75.8\%) accepted group housing for calves, with $17.8 \%$ choosing to explain their acceptance as dependent on (in decreasing order of frequency): socialization, space allowance, conditional acceptance, and environmental quality.
Approximately half of those who shared their reasoning found group housing acceptable because of socialization opportunities afforded to calves (50.8\%). Many of these individuals gave some description of play behavior (e.g., "community" [PA1154], "companionship" [PA436], or "herd mentality" [PA861]). Participants also valued group housing due to increased space allowance $(32.8 \%)$. As with other housing systems, some adults who accepted group housing nonetheless raised conditional acceptance (18.6\%; e.g., "I like the social piece to it - cows like to be in herds; [only] if they do not harm each other" [PA660]). Relatively few also referenced acceptable environmental quality $(7.3 \%)$ of group housing (e.g., "[it] appears clean [and has] access to food and water... [the calves are] sheltered and safe" [PA205]).

\section{Reasons for Calf Housing Nonacceptance: Adults}

Participants also shared reasons for nonacceptance (rejection) of the calf housing options (Table 3), often referencing multiple themes within their responses.

Individual Housing. Forty-seven percent of adults disagreed that individual calf housing was acceptable, with $33.8 \%$ of these choosing to share their reasoning behind their choice. Participants who indicated that in-

Table 3. Adult participants' use of themes to justify nonacceptance of housing options for dairy calves ${ }^{1}$

\begin{tabular}{|c|c|c|c|c|}
\hline Theme & Description of theme & $\begin{array}{c}\text { Individual } \\
\text { housing }\end{array}$ & $\begin{array}{c}\text { Pair } \\
\text { housing }\end{array}$ & $\begin{array}{l}\text { Group } \\
\text { housing }\end{array}$ \\
\hline Calf health & Concerns regarding disease control and resource availability & $\mathrm{N} / \mathrm{A}$ & 11.6 & 32.4 \\
\hline Space allowance & Space allowance as inadequate & 29.8 & 69.6 & 20.6 \\
\hline Unnaturalness & Housing system as unnatural, e.g., lacking pasture or access to dam & 10.1 & 11.6 & 52.9 \\
\hline
\end{tabular}

${ }^{1}$ Percentage of those participants who strongly disagree or disagree with the statement "This housing is acceptable to me." N/A = the theme was not mentioned in reasons for preference or acceptance of housing options. 
dividual calf housing was unacceptable often referenced similar themes as those who accepted individual housing (e.g., socialization and space allowance), but found these issues to be insufficiently met in this system. For example, most were dissatisfied by a lack of socialization (72.1\%), commenting that calves were "painfully isolated" [PA436] and that "they are herd animals; they shouldn't be isolated from their kind" [PA162]. They also worried that inadequate space allowance $(29.8 \%)$ prevented calves from expressing natural behaviors (e.g., "they do not have enough space for [the] calves to run," [PA716]). Finally, some (10.1\%) rejected individual calf housing because it was seen as unnatural (e.g., "[calves] need green space" [PA788]).

Pair Housing. Relatively fewer participants rejected pair housing as an acceptable option (14.1\%), with $37.3 \%$ of these individuals providing 4 themes for their decision (in decreasing order of frequency): space allowance $(69.6 \%)$; socialization (27.5\%; e.g., "imagine being stuck with one person for life" [PA1277]), calf health $(11.6 \%$, with focuses on possible disease spread and uneven feed consumption), and unnaturalness (11.6\%, due to lack of pasture access and separation from the dam).

Group Housing. Only $7.4 \%$ of all participants found group housing unacceptable; $35.1 \%$ of this group chose to provide reasons raising 3 themes (in decreasing order of frequency): unnaturalness, calf health, and space allowance. Group housing was most commonly rejected because it was felt to be unnatural (52.9\%) due to lack of pasture access or separation from the dam. Others rejected group housing because of calf health (32.4\%) concerns that calves could "spread infection" [PA152]. Finally, some rejected group housing due to insufficient space allowance (20.6\%).

Rejection of all Housing Options. Few (3.1\%) of the adults in the current study indicated that all 3 housing options were not acceptable to them, with reasons focused mainly on unnaturalness (e.g., "still looks like access to outdoors is limited" [PA175] or "not near mom, no field" [PA1293]).

\section{Relationship Between Demographics and Youth Reasons for Calf Housing Preference}

No relationship was found between youth use of calf housing themes and any of the collected demographics with the exception of gender, which was associated with use of the socialization, space allowance, affective state, and compromise between housing systems themes $(P$ $=0.016)$. Male youth more frequently referenced socialization compared with female youth $(44.8 \pm 3.7 \%$ vs. $39.0 \pm 2.8 \%$, respectively), and less frequently referenced space allowance $(33.1 \pm 3.5 \%$ vs. $37.7 \pm 2.8 \%$, respectively), affective state $(3.3 \pm 1.3 \%$ vs. $6.7 \pm$
$1.4 \%$, respectively), and compromise between housing systems $(0.6 \pm 0.6 \%$ vs. $3.9 \pm 1.1 \%$, respectively).

\section{DISCUSSION}

As consumers become more interested in where their food comes from, it is of increasing importance to better understand public views relative to the welfare of farmed animals, including dairy cattle. Relatively little research has focused on how members of the public perceive issues relative to the dairy calf. A key finding of the current study was that social housing of calves garnered majority support among our respondents.

\section{Public Values of Calf Housing Options}

Farm animal welfare has emerged as a major social issue (Clark et al., 2016) and public sentiment about animal welfare is increasingly influential over livestock production practices (Mench, 2008; Smithson et al., 2014). Most of the literature in this area focuses on adults (Jamieson et al., 2012, 2015); however, youth perspectives are also important, in part because children are a critical part of family purchasing dynamics (Sharma and Sonwaney, 2014).

Overall, youth and adults in the current study expressed strong support that provisions be made to accommodate the value of natural living in dairy calves, although this value was more frequently expressed by those preferring or accepting some level of social housing (pair or group) as opposed to individual housing. That participants focused on elements related to natural living (e.g., behavioral freedom, socialization, choice, space allowance) supports previous findings that UK adolescents also place importance on provision of adequate space and behavioral freedom for farm animals (Jamieson et al., 2012; Jamieson et al., 2015). More broadly, abundant literature suggests that lay adults likewise place priority on natural living in order for farm animals to have a good life (Spooner et al., 2014; Ventura et al., 2016; Heise and Theuvsen, 2018). Others have found that "naturalness" is a highly desired trait for the modern farm (Cardoso et al., 2016; Yunes et al., 2017). Moreover, concerns that modern farms have little regard for natural living (Vanhonacker et al., 2007) and inhibit animals from expressing natural behaviors seem to be a driving factor underlying public concern for livestock welfare (Paarlberg, 2009). The small proportion $(3.1 \%)$ of adult participants in the current study who indicated all 3 housing options were unacceptable to them explained their decisions in terms of these options being unnatural, with pasture access being the main concern, followed by access to the dam. Overall, these findings contribute to an emerging consensus that 
provisions for natural living (e.g., outdoor access, social and other natural behaviors) are necessary components for public expectations for farm animal welfare (Prickett, 2008; Cardoso et al., 2016; Ventura et al., 2016).

\section{Relationship Between Demographics and Calf Housing Preference or Acceptance}

The results of the current study are consistent with other work suggesting an association between area of residence and animal welfare attitudes (Serpell, 2005; Herzog, 2007). Previous research suggests that rural residents possess greater awareness of farming issues and more detailed knowledge of reasons underlying farming practices (Harper and Makatouni, 2002), though rural versus urban backgrounds do not always associate with concerns about animal welfare (Kendall et al., 2006). In the current study, acceptance and preference of individual calf housing was more frequent among individuals from rural backgrounds as well as adult individuals who had previously worked with livestock, which supports previous work connecting farming experience with views toward animal welfare (Vanhonacker et al., 2007).

We anticipated that having a loved one in the dairy industry would contribute to approval of more common management practices and that therefore, adult participants would be more accepting of individual housing. To our knowledge, this is the first study to identify associations between interpersonal relationships and dairy calf management views among the adult public. Our finding that people with farm experience were more accepting of individual calf housing was also expected, as they are also likely to have more knowledge of the reasons behind farming practices, or alternatively may be more comfortable with cultural norms associated with farming (or both). However, what is interesting here is that previous visits to farms was associated with more frequent acceptance of pair housing for dairy calves, suggesting that engaging the adult public via farm visits may offer a reasonable way for industry to increase public acceptance of "compromise" solutions to animal practices. However, past research has indicated that increasing public knowledge about farming through educational farm visits has segmented effects on public perception and concerns about livestock farming, with some becoming more satisfied and others more concerned about animal care on farms (Barbieri et al., 2016; Ventura et al., 2016). Indeed, lower support was found for individual calf housing among people who had visited dairy-related sites at the state fair, which may support the findings by Barbieri et al. (2016) and Ventura et al. (2016).
Finally, we examined social media use and potential relationships with housing preference among youth and acceptance among adults. Previous research has indicated that social media can affect demand of certain animal products (Tonsor and Olynk, 2011), with beef being less affected than pork or poultry. The public is increasingly exposed to animal agriculture, including undercover activist videos exposing abusive practices, via an increasingly broad range of media (Tiplady et al., 2013). This exposure may negatively affect public perception of the livestock sector indefinitely (Tonsor et al., 2009). No associations were found in the current study between calf housing preference among youth and social media use as a whole, suggesting that the youth in our study may not have been exposed to animal husbandry issues like adults, or their social media presence may be less prominent compared with adults. To test this theory, we could have asked participants to indicate amount of time spent on social media per week and investigated if time spent on social media had associations with housing preference. However, we did find an association among adults and acceptance of individual calf housing, which was more frequent among adult participants who did not access common social media platforms. One potential explanation for this finding is that nonusers of social media may not be exposed to animal welfare campaigns against common agriculture practices, nor witness undercover videos documenting cases of abuse, though this hypothesis warrants further investigation.

\section{Survey Considerations}

Our results may not be representative of all fair goers, as participants of this survey needed to choose to visit the Driven to Discover building and hence may have been more interested in research and science than the general population. However, our survey sample does align with similar proportions of urban residents in the state of Minnesota (Minnesota State Demographic Center, 2017).

\section{CONCLUSIONS}

To our knowledge, this is the first study to explore views on dairy calf housing among American youth and adults. Both youth and adults overwhelmingly preferred the group housing option for dairy calves, a preference driven in large part by perceived advantages related to increased space allowance and opportunity for the calves to socialize. These data suggest that public desires for natural living in dairy farming may start at an early age. We conclude that adopting calf 
housing options that promote socialization and greater behavioral freedom for calves is likely to benefit the dairy sector's public image and social sustainability.

\section{ACKNOWLEDGMENTS}

We thank the University of Minnesota's Driven to Discover Research Facility for choosing our research to be featured at the 2018 Minnesota State Fair and providing us with supplies and space to conduct this research. We thank Mateus Peiter and Hannah Phillips (University of Minnesota, St. Paul) and volunteers Tony Swanson and Brian Ventura (Minneapolis, MN) for helping us administer the survey and recruit participants. Last, we thank the public who participated in our study and made this research possible. The study was partially supported by USDA-Hatch and Department of Animal Science (University of Minnesota, St. Paul) funding. The authors have not stated any conflicts of interest.

\section{REFERENCES}

Allen, I. E., and C. A. Seaman. 2007. Likert scales and data analyses. Qual. Prog. 40:64-65.

Babu, L. K., H. N. Pandey, and A. Sahoo. 2004. Effect of individual versus group rearing on ethological and physiological responses of crossbred calves. Appl. Anim. Behav. Sci. 87:177-191. https://doi .org/10.1016/j.applanim.2004.01.006.

Barbieri, C., S. Xu, C. Gil-Arroyo, and S. R. Rich. 2016. Agritourism, farm visit, or ...? A branding assessment for recreation on farms. J. Travel Res. 55:1094-1108. https://doi.org/10.1177/ 0047287515605930.

Boogaard, B. K., S. J. Oosting, and B. B. Bock. 2008. Defining sustainability as a socio-cultural concept: Citizen panels visiting dairy farms in the Netherlands. Livest. Sci. 117:24-33. https://doi.org/ 10.1016/j.livsci.2007.11.004.

Busch, G., D. M. Weary, A. Spiller, and M. A. G. von Keyserlingk. 2017. American and German attitudes towards cow-calf separation on dairy farms. PLoS One 12:e0174013 https://doi.org/10.1371/ journal.pone.0174013.

Cardoso, C. S., M. J. Hötzel, D. M. Weary, J. A. Robbins, and M. A. G. von Keyserlingk. 2016. Imagining the ideal dairy farm. J. Dairy Sci. 99:1663-1671. https://doi.org/10.3168/jds.2015-9925.

Cardoso, C. S., M. A. G. Von Keyserlingk, and M. J. Hötzel. 2017. Brazilian citizens: Expectations regarding dairy cattle welfare and awareness of contentious practices. Animals (Basel) 7:89-104. https://doi.org/10.3390/ani7120089.

Clark, B., G. B. Stewart, L. A. Panzone, I. Kyriazakis, and L. J. Frewer. 2016. A systematic review of public attitudes, perceptions and behaviours towards production diseases associated with farm animal welfare. J. Agric. Environ. Ethics 29:455-478. https://doi .org/10.1007/s10806-016-9615-x.

Coffey, A., and P. Atkinson. 1994. Making Sense of Qualitative Data: Complementary Research Strategies. A. Coffey and P. Atkinson, ed. Sage, Thousand Oaks, CA.

Costa, J. H. C., R. R. Daros, M. A. G. von Keyserlingk, and D. M. Weary. 2014. Complex social housing reduces food neophobia in dairy calves. J. Dairy Sci. 97:7804-7810. https://doi.org/10.3168/ jds.2014-8392.

Costa, J. H. C., R. K. Meagher, M. A. G. von Keyserlingk, and D. M. Weary. 2015. Early pair housing increases solid feed intake and weight gains in dairy calves. J. Dairy Sci. 98:6381-6386. https:// doi.org/10.3168/jds.2015-9395.
Costa, J. H. C., M. A. G. von Keyserlingk, and D. M. Weary. 2016. Invited review: Effects of group housing of dairy calves on behavior, cognition, performance, and health. J. Dairy Sci. 99:2453-2467. https://doi.org/10.3168/jds.2015-10144.

de Passillé, A. M., J. Rushen, and D. M. Weary. 2004. Designing good environments and management for calves. Adv. Dairy Technol. 16:75-89.

De Paula Vieira, A., M. A. G. von Keyserlingk, and D. M. Weary. 2010. Effects of pair versus single housing on performance and behavior of dairy calves before and after weaning from milk. J. Dairy Sci. 93:3079-3085. https://doi.org/10.3168/jds.2009-2516.

Harper, G. C., and A. Makatouni. 2002. Consumer perception of organic food production and farm animal welfare. Br. Food J. 104:287-299. https://doi.org/10.1108/00070700210425723.

Heise, H., and L. Theuvsen. 2018. Citizens' understanding of welfare of animals on the farm: An empirical study. J. Appl. Anim. Welf. Sci. 21:153-169. https://doi.org/10.1080/10888705.2017.1400439.

Herzog, H. A. 2007. Gender differences in human-animal interactions: A review. Anthrozoos 20:7-21. https://doi.org/10.2752/ 089279307780216687

Jamieson, J., M. Reiss, D. Allen, L. Asher, C. Wathes, and S. Abeyesinghe. 2012. Measuring the success of a farm animal welfare education event. Anim. Welf. 21:65-75. https://doi.org/10.7120/ 096272812799129402.

Jamieson, J., M. J. Reiss, D. Allen, L. Asher, M. O. Parker, C. M. Wathes, and S. M. Abeyesinghe. 2015. Adolescents care but don't feel responsible for farm animal welfare. Soc. Anim. 23:269-297. https://doi.org/10.1163/15685306-12341283.

Jeong, H.-J., and W.-C. Lee. 2016. The level of collapse we are allowed: Comparison of different response scales in safety attitudes questionnaire. Biometrics Biostat. Int. J. 4:128-134. https://doi .org/10.15406/bbij.2016.04.00100.

Keil, N. M., and W. Langhans. 2001. The development of intersucking in dairy calves around weaning. Appl. Anim. Behav. Sci. 72:295308. https://doi.org/10.1016/S0168-1591(00)00207-0.

Kendall, H. A., L. M. Lobao, and J. S. Sharp. 2006. Public concern with animal well-being: Place, social structural location, and individual experience. Rural Sociol. 71:399-428. https://doi.org/10 .1526/003601106778070617.

Mench, J. A. 2008. Farm animal welfare in the U.S.A.: Farming practices, research, education, regulation, and assurance programs. Appl. Anim. Behav. Sci. 113:298-312. https://doi.org/10.1016/j .applanim.2008.01.009.

Minnesota State Demographic Center. 2017. Greater Minnesota: Refined and revisited. Accessed Jan. 7, 2020. https://mn.gov/admin/ assets/greater-mn-refined-and-revisited-msdc-jan2017_tcm36 -273216.pdf.

NAHMS-USDA (National Health Monitoring System-US Department of Agriculture). 2016. Dairy 2014. Part I: Reference of Dairy Cattle Health and Management Practices in the United States. Accessed Jun. 20, 2019. https://www.aphis.usda.gov/animal_health/ nahms/dairy/downloads/dairy14/Dairy14_dr_PartIII.pdf.

Paarlberg, R. 2009. The ethics of modern agriculture. Society 46:4-8. https://doi.org/10.1007/s12115-008-9168-3.

Prickett, R. W., B. Norwood, and J. Lusk. 2010. Consumer preferences for farm animal welfare: Results from a telephone survey of U.S. households. Anim. Welf. 19:335-347.

Robbins, J. A., C. Roberts, D. M. Weary, B. Franks, and M. A. G. von Keyserlingk. 2019. Factors influencing public support for dairy tie stall housing in the U.S. PLoS One 14:e0216544 https://doi.org/ 10.1371/journal.pone.0216544.

Roedder, D. L. 1981. Age differences in children's responses to television advertising: An information-processing approach. J. Consum. Res. 8:144-153. https://doi.org/10.1086/208850.

Schuppli, C. A., M. A. G. von Keyserlingk, and D. M. Weary. 2014. Access to pasture for dairy cows: Responses from an online engagement. J. Anim. Sci. 92:5185-5192. https://doi.org/10.2527/ jas.2014-7725.

Schwartz, S. H. 1992. Universals in the content and structure of values: Theoretical advances and empirical tests in 20 countries 
Adv. Exp. Soc. Psychol. 25:1-65. https://doi.org/10.1016/S0065 -2601(08)60281-6.

Schweikhardt, D. B., and W. P. Browne. 2001. Politics by other means: The emergence of a new politics of food in the United States. Rev. Agric. Econ. 23:302-318. https://doi.org/10.1111/1467-9353 .00063 .

Serpell, J. A. 2005. Factors influencing veterinary students' career choices and attitudes to animals. J. Vet. Med. Educ. 32:491-496. https://doi.org/10.3138/jvme.32.4.491.

Sharma, A., and V. Sonwaney. 2014. Theoretical modeling of influence of children on family purchase decision making. Procedia Soc. Behav. Sci. 133:38-46. https://doi.org/10.1016/j.sbspro.2014.04.167.

Smithson, K., M. Corbin, J. L. Lusk, and F. B. Norwood. 2014. Predicting state-wide votes on ballot initiatives to ban battery cages and gestation crates. J. Agric. Appl. Econ. 46:107-124. https://doi .org/10.1017/S1074070800000663.

Spooner, J. M., C. A. Schuppli, and D. Fraser. 2014. Attitudes of Canadian citizens toward farm animal welfare: A qualitative study. Livest. Sci. 163:150-158. https://doi.org/10.1016/j.livsci.2014.02 .011.

Tiplady, C. M., D. A. B. Walsh, and C. J. C. Phillips. 2013. Public response to media coverage of animal cruelty. J. Agric. Environ. Ethics 26:869-885. https://doi.org/10.1007/s10806-012-9412-0.

Tonsor, G. T., and N. J. Olynk. 2011. Impacts of animal well-being and welfare media on meat demand. J. Agric. Econ. 62:59-72. https://doi.org/10.1111/j.1477-9552.2010.00266.x.

Tonsor, G. T., N. J. Olynk, and C. A. Wolf. 2009. Media coverage of animal handling and welfare: Influence on meat demand. Pages 1-35 in Proc. Agricultural and Applied Economics Association Annual Meeting, Milwaukee, WI. https://doi.org/10.22004/ag .econ.49338.
Vanhonacker, F., W. Verbeke, E. Van Poucke, and F. A. M. Tuyttens. 2007. Segmentation based on consumers' perceived importance and attitude toward farm animal welfare. Int. J. Sociol. Agric. Food 15:84-100.

Ventura, B. A., M. A. G. Von Keyserlingk, H. Wittman, and D. M. Weary. 2016. What difference does a visit make? Changes in animal welfare perceptions after interested citizens tour a dairy farm. PLoS One 11:e0154733 https://doi.org/10.1371/journal.pone .0154733 .

Warnick, V. D., C. W. Arave, and C. H. Mickelsen. 1977. Effects of group, individual, and isolated rearing of calves on weight gain and behavior. J. Dairy Sci. 60:947-953. https://doi.org/10.3168/ jds.S0022-0302(77)83968-4.

Wolf, C. A., G. T. Tonsor, M. G. S. McKendree, D. U. Thomson, and J. C. Swanson. 2016. Public and farmer perceptions of dairy cattle welfare in the United States. J. Dairy Sci. 99:5892-5903. https:// doi.org/10.3168/jds.2015-10619.

Yunes, M. C., M. A. G. Von Keyserlingk, and M. J. Hötzel. 2017. Brazilian citizens' opinions and attitudes about farm animal production systems. Animals (Basel) 7:1-75. https://doi.org/10.3390/ ani7100075.

\section{ORCIDS}

Rielle K. Perttu ๑ https://orcid.org/0000-0003-0942-0899

Beth A. Ventura (๑) https://orcid.org/0000-0001-9476-6901

Marcia I. Endres () https://orcid.org/0000-0002-1798-3432 